\title{
DENSIDADE DE PLANTIO E RENDIMENTO DE FRUTOS DO MELOEIRO (Cucumis melo L.) ${ }^{1}$
}

\author{
PAULO SÉRGIO LIMA E SILVA², JAILTON ROBERTO DA FONSECA³, JAEDSON CLAÚDIO ANUNCIATO MOTA", \\ JAEVESON DA SILVA ${ }^{5}$
}

\begin{abstract}
RESUMO - O objetivo do trabalho foi avaliar os efeitos da densidade de plantio $(7 ; 10 ; 13 ; 16 ; 19 ; 22$ e 25 mil plantas/ha) sobre o rendimento de frutos do meloeiro, cv. Gold Pride. As densidades foram obtidas mantendo-se constante $(2,0 \mathrm{~m})$ o espaçamento entre fileiras e variando-se o espaçamento entre covas. O trabalho foi realizado em Tibau-RN, com irrigação por gotejamento. Utilizou-se o delineamento de blocos ao acaso, com sete repetições. O aumento da densidade de plantio aumentou o número e a massa de frutos, totais, comercializáveis e não-comercializáveis, reduziu o comprimento e o diâmetro dos frutos comercializáveis, mas não influenciou o teor de sólidos solúveis dos frutos comercializáveis.
\end{abstract}

Termos para indexação: melão, população de plantas, espaçamento.

\section{PLANT DENSITY AND FRUIT YIELD OF MUSKMELON (Cucumis melo L.)}

ABSTRACT - The objective of this work was to evaluate the effects of plant density $\left(7,10,13,16,19,22\right.$ and 25 thousands plants ha $\left.{ }^{-1}\right)$ on fruit yield of yellow melon (Cucumis melo L.), cv. Gold Pride. The plant densities were obtained using the same spacing (2.0 m) between rows, but varying spacing between plants at same row. The experiment was carried out at Tibau-RN county, Brazil. The complete randomized design with seven replications was used. The increase of plant density increased the total number and the total weight of the fruit, the number and weight of marketable fruits and the number and weight of unmarketable fruits, but decreased length and diameter of marketable fruits, but did not influenced total soluble solid content of melon.

Index terms: melon, plant population, spacing.

\section{INTRODUÇÃO}

A região nordestina brasileira é responsável por mais de $90 \%$ da produção de melão do País. O Estado do Rio Grande do Norte é o maior produtor brasileiro e, em 1996, contribuiu com 63\% da produção (Grangeiro et al., 1999a).

No referido Estado, a região compreendida pelo município de Mossoró-Açu apresenta relevante importância na produção de melão. Nessa região, encontra-se grande variação nos sistemas de produção do meloeiro. Existem desde pequenos produtores a grandes empresas agrícolas. Os níveis tecnológicos, incluindo cultivares e práticas culturais, são também bastante variáveis. Na realidade, muitas das tecnologias praticadas com o meloeiro e com outras culturas foram importadas de outras regiões, até porque, a citada cultura tem sido relativamente pouco estudada no Rio Grande do Norte. Assim, muitas práticas culturais são adotadas após tentativas de erro-acerto por vários agricultores. No que se refere à densidade de plantio, Almeida (1992), em levantamento feito na região, concluiu que o espaçamento adotado pelos produtores varia de 2,0 a 2,5 m entre fileiras e 0,3 a $1,0 \mathrm{~m}$ entre plantas, com 1 ou 2 plantas por cova, o que corresponde de 4 mil a 30 mil plantas/ha.

As baixas densidades de plantio adotadas pelos produtores do Rio Grande do Norte, no cultivo do meloeiro, podem estar constituindo-se em problema limitante ao aumento do rendimento. Vários autores (Nerson, 1999; Zahara, 1972; Granjeiro et al., 1999a) têm demonstrado que o aumento da densidade de plantio pode proporcionar aumentos no rendimento de melão. É bem verdade que nem sempre o aumento da densidade proporciona aumento do rendimento de frutos (Faria et al., 2000). Outro aspecto que aumenta o interesse dos pesquisadores pelo estudo da densidade de plantio em meloeiro, e em outras culturas, é que ela depende das cultivares avaliadas (Zahara, 1972) e das condições ambientais (Paris et al., 1988).

O objetivo do presente trabalho foi avaliar os efeitos de sete densidades de plantio sobre o rendimento e a qualidade de frutos da cultivar Gold Pride.

\section{MATERIALEMÉTODOS}

O experimento foi realizado na empresa "Agrícola Cajazeira”, localizada no município de Tibau-RN, distante $30 \mathrm{~km}$ da sede do município de Mossoró-RN (latitude $5^{\circ} 11^{\prime} \mathrm{S}$, longitude $37^{\circ} 20^{\prime} \mathrm{W}$, e altitude de $18 \mathrm{~m}$, aproximadamente), principal cidade da região Oeste Potiguar. A temperatura máxima do ar nos meses de setembro, outubro e novembro foi $36,7^{\circ} \mathrm{C} ; 37,4^{\circ} \mathrm{C}$ e $36,8^{\circ} \mathrm{C}$, respectivamente. Os valores respectivos para a temperatura mínima do ar foram $25,5^{\circ} \mathrm{C} ; 21,5^{\circ} \mathrm{C}$ e $21,1^{\circ} \mathrm{C}$

O solo, um Alfissolo Vermelho-Amarelo (Podzólico VermelhoAmarelo), foi preparado com uma aração e duas gradagens e recebeu, como adubação de plantio, cerca de 10 t/ha de esterco bovino curtido, em sulcos com a profundidade aproximada de $0,20 \mathrm{~m}$. Após a aplicação do esterco, os sulcos foram cobertos com solo. A semeadura foi feita à profundidade de 1,0 cm, em 09-09-1999, em covas abertas acima dos sulcos onde foi aplicado o esterco. Aos cinco dias após a semeadura, realizou-se um replantio, para redução do número de falhas.

A cultivar Gold Pride foi submetida às densidades de plantio de $7 ; 10 ; 13 ; 16 ; 19 ; 22$ e 25 mil plantas/ha. Tais populações foram obtidas mantendo-se fixo $(2,0 \mathrm{~m})$ o espaçamento entre fileiras e variando-se o espaçamento entre covas. Utilizou-se o delineamento de blocos completos casualizados com sete repetições. Cada parcela ficou constituída por três fileiras com 6,0 m de comprimento. Como área útil, considerouse a ocupada pelas plantas da fileira central, eliminando-se uma cova em cada extremidade.

O experimento foi irrigado por gotejamento. A água de irrigação foi aplicada durante $2 \mathrm{~h}$ do $1^{0}$ ao $5^{0}$ dia após o plantio (dap); $1 \mathrm{~h}$ do $6^{0}$ ao $12^{\circ}$ e do $14^{0}$ ao $16^{0} ; 1 \mathrm{~h} 30$ no $18^{0}, 20^{\circ}$ e $22^{0} ; 2$ h no $25^{\circ} ; 2 \mathrm{~h} 30$ do $26^{0}$ ao $30^{\circ}$; $3 \mathrm{~h} 30$ do $31^{\circ}$ ao $35^{\circ} ; 4$ h do $36^{\circ}$ ao $40^{\circ} ; 5$ h do $41^{\circ}$ ao $56^{\circ}$; e 3 h 30 do $57^{\circ}$ ao $63^{0}$ dap. A quantidade d'água aplicada por hora foi de $23 \mathrm{~m}^{3} / \mathrm{ha}$.Os adubos, aplicados via água de irrigação, estão discriminados na Tabela 1. As pragas e doenças foram controladas previamente por pulverizações realizadas aos $12 ; 15 ; 20 ; 33$ e 41 dias após a semeadura.

Duas colheitas foram realizadas no período de 60 a 67 dias após o semeio. Foram avaliados os números e massas de frutos, totais e comercializáveis, o comprimento, a largura e o teor de sólidos solúveis dos frutos comercializáveis. Como comercializáveis, foram considerados os frutos sem deformações, manchas e evidências aparentes de problemas fisiológicos ou do ataque de doenças e pragas. O comprimento e a largura dos frutos foram estimados medindo-se, com um

\footnotetext{
${ }^{1}$ (Trabalho 006/2003). Recebido: 08/11/2002. Aceito para publicação: 05/06/2003. Apresentado no XVII Congresso Brasileiro de Fruticultura.

${ }^{2}$ Prof. Adj., Esc. Sup. de Agric. Mossoró (ESAM). Cx. Postal 137 - 59625-900 - Mossoró-RN. Fone: (084) 312-2100. E-mail: paulosergio@ esam.br

${ }^{3}$ Eng. Agr., Agrícola Cajazeira, BR 304, km 94, Aracati-CE.

${ }^{4}$ Eng. Agr., estudante de Agronomia da ESAM. Cx. Postal 137 - 59625-900 - Mossoró-RN. Fone: (084)312-2100

${ }^{5}$ Eng. Agr., estudante de Mestrado da ESAM. Cx. Postal 137 - 59625-900 - Mossoró-RN. Fone: (084)312-2100
} 
TABELA 1- Fertilizantes aplicados à cultura do meloeiro, durante o período de $1 \mathrm{a} 75$ dias após o plantio.

\begin{tabular}{|c|c|c|c|c|c|c|c|}
\hline $\begin{array}{l}\text { Dias após o } \\
\text { plantio }\end{array}$ & \multicolumn{7}{|c|}{ Fertilizante aplicado (kg/ha, exceto ácido fosfórico, em 1/ha) } \\
\hline 01 a 05 & - & 1,25 & - & 1,25 & - & 1,67 & - \\
\hline 06 a 10 & 5,00 & 2,92 & - & 2,08 & - & 2,92 & - \\
\hline 21 a 27 & 5,83 & - & 4,58 & 11,25 & 1,25 & 9,17 & 6,67 \\
\hline 28 a 37 & 4,58 & 4,58 & 6,67 & 7,50 & 9,17 & 6,67 & 4,58 \\
\hline 38 a 48 & 1,25 & - & 13,33 & 2,08 & - & 2,92 & - \\
\hline
\end{tabular}

paquímetro, todos os frutos comercializáveis de cada parcela. Na primeira colheita, foram retirados três frutos, de forma aleatória, dentre os comercializáveis, para a determinação do teor de sólidos solúveis. Os frutos foram cortados longitudinalmente ao meio, e as polpas de uma das metades de cada fruto foram trituradas em conjunto num processador doméstico de alimentos. O material resultante foi filtrado em tecido de náilon e, em três gotas do suco obtido, determinou-se o teor de sólidos solúveis totais, usando-se um refratômetro digital marca Atago, modelo Palette 100. Em cada amostra, foram feitas três leituras. A média dessas leituras representou o valor da parcela.

As análises de variância e de regressão foram efetuadas com os softwares SPSS-PC (Norusis, 1990) e Table Curve (Jandel Scientific, 1991), respectivamente.

\section{RESULTADOS E DISCUSSÃO}

O aumento da densidade de plantio aumentou os números (Figura 1) e os pesos (Figura 2) totais de frutos e de frutos comercializáveis do meloeiro Gold Pride. Acréscimos em tais características, em conseqüência do aumento da densidade de plantio, também foram observados por outros autores (Grangeiro et al., 1999a; Mendlinger, 1994; Paris et al., 1988; Zahara, 1972), com os aumentos dependendo (Zahara, 1972) ou não (Grangeiro et al., 1999a) da cultivar. Zahara (1972) verificou, como no presente trabalho, aumentos contínuos no número de frutos comercializáveis de uma cultivar, mas decréscimos nesta característica de outra cultivar, a partir de 16 mil plantas/ha, com o aumento da densidade de plantio.

É bem aceito que as equações de regressão ajustadas devem ser consideradas apenas no intervalo estudado. Contudo, parece razoável admitir-se, pelas curvas apresentadas nas Figuras 1 e 2, que o número e o peso totais e de frutos comercializáveis do meloeiro Gold Pride poderiam ser aumentados com densidades de plantio superiores a 25 mil plantas/ha. Os resultados de Grangeiro et al. (1999b), obtidos com três cultivares, sob condições edafoclimáticas mais ou menos semelhantes às do presente estudo, apóiam esta suposição. Deve ser mencionado, entretanto, que alguns agricultores relutam em usar maiores densidades de plantio, para reduzir o gasto com sementes, que são adquiridas a preços elevados.

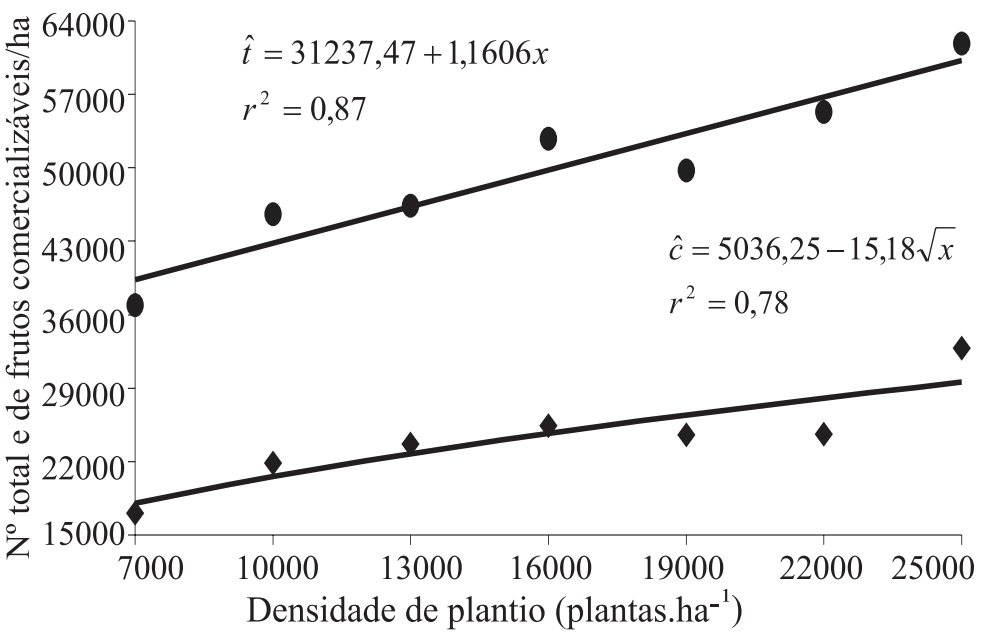

FIGURA 1 - Números total ( $\mathrm{t}$ ) e de frutos comercializáveis (c) da cultivar de meloeiro Gold Pride em razão da densidade de plantio.
Constata-se que o número e o peso dos frutos refugados também aumentaram com o aumento da densidade de plantio (Figuras 1 e 2). A diferença entre as curvas ajustadas para o número total de frutos e o número de frutos comercializáveis indica que a estimativa do número de frutos refugados seria dada por 26.201,22 +1,1606 ( $x+13,08 \mathrm{vx})$, onde $x$ é a densidade de plantio. De acordo com essa estimativa, nas populações de 7000 e 25000 plantas ha $^{-1}$, os números de frutos refugados seriam de 27.471 e 53.269, respectivamente. A estimativa do peso de frutos refugados, utilizando-se do mesmo raciocínio, seria dada por 30.867,16$30.072 .190 / x$. Neste caso, as perdas de frutos refugados, em termos de $\mathrm{kg} / \mathrm{ha}$, seriam de 4.296 e 29.664, nas populações de 7.000 e 25.000 plantas ha $^{-1}$, respectivamente. Nerson (1999) e Grangeiro et al. (1999a) também verificaram aumentos na percentagem de frutos refugados com o aumento da densidade de plantio.

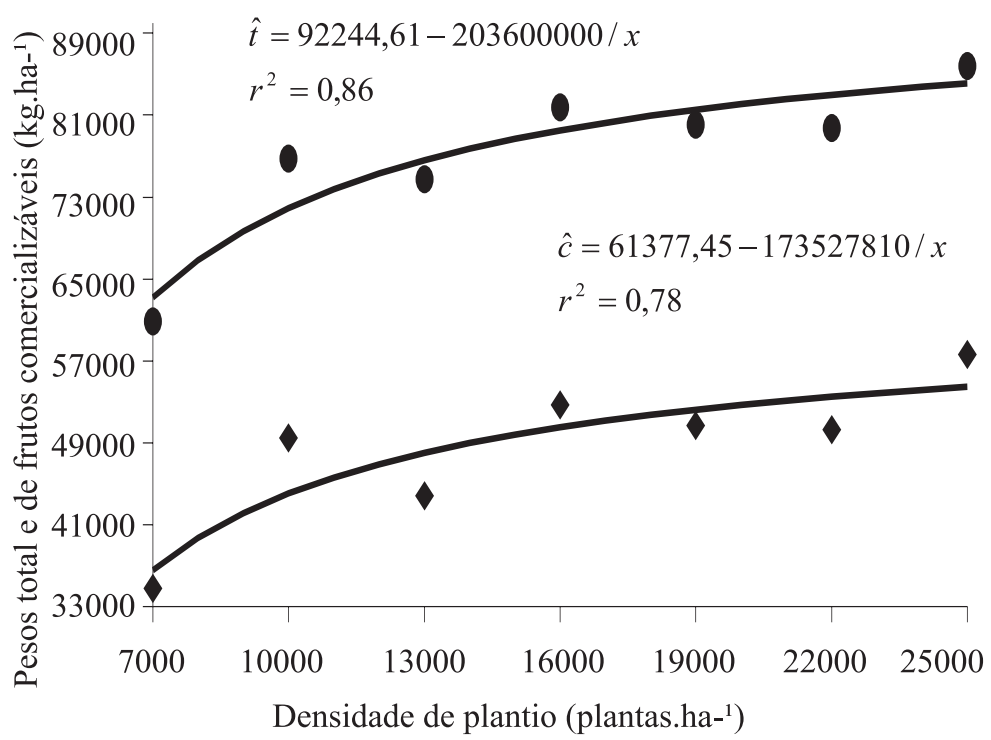

FIGURA 2 - Pesos total (t) e de frutos comercializáveis (c) da cultivar de meloeiro Gold Pride em razão da densidade de plantio.

Tanto o comprimento como a largura dos frutos comercializáveis foram reduzidos com o aumento da densidade de plantio (Figura 3). Portanto, maiores densidades de plantio proporcionaram maiores números (Figura 1) de frutos menores. Maiores quantidades de frutos menores, com o aumento da densidade de plantio, foram observadas também por Mendlinger (1994) e Grangeiro et al. (1999a). As reduções nas dimensões dos frutos devem resultar do aumento da competição entre plantas por luz e nutrientes, que ocorre com o aumento da densidade de plantio. A competição, embora aumente o número e o peso de frutos/ha, reduz as dimensões dos frutos de cada planta.

Não houve efeito da densidade de plantio sobre o teor de sólidos solúveis. O valor médio obtido foi de $8,70 \%$. Este resultado é concordante com os observados por alguns autores (Faria et al., 2000; Grangeiro et al., 1999a; Kultur et al., 2001). Contudo, deve ser mencionado que Zahara (1972) contatou aumento da percentagem de sacarose, com a redução da densidade de plantio, nos frutos de duas cultivares. Provavelmente, o teor de sólidos solúveis somente seja alterado pela densidade de plantio, com a adoção de maiores densidades de plantio. 
No presente trabalho, foram avaliadas densidades variando de 7 a 25 mil plantas/ha, enquanto Zahara (1972) avaliou densidades de 7 a 63 mil plantas/ha. Nas maiores densidades, a competição entre plantas por luz, água e nutrientes pode reduzir a produção de fotossintatos, influenciando negativamente o TSST.

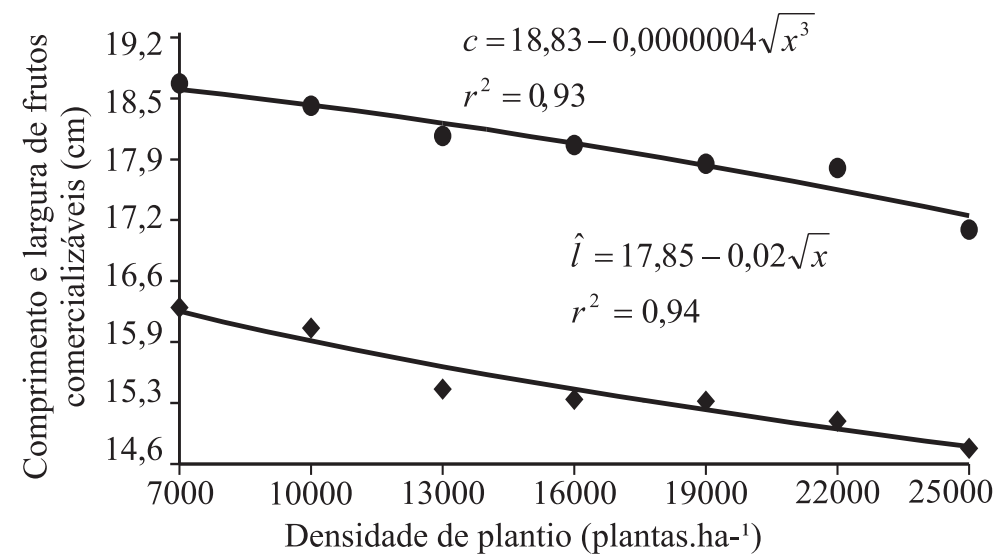

FIGURA 3 - Comprimento (c) e largura (1) de frutos comercializáveis da cultivar de meloeiro Gold Pride em razão da densidade de plantio.

\section{CONCLUSÕES}

$\mathrm{O}$ aumento da densidade de plantio aumentou o número e o peso dos frutos totais, comercializáveis e refugados, reduziu o comprimento e o diâmetro dos frutos comercializáveis, mas não influenciou o teor de sólidos solúveis dos melões comercializáveis.

\section{REFERÊNCIASBIBLIOGRÁFICAS}

ALMEIDA, J.H.S. Sistema de produção de melão cv. Valenciano Amarelo para o Estado do Rio Grande do Norte. 992.45 f., Monografia (Trabalho de Graduaçãoem Agranomia) - Escola Superior de Agricultura de Mossoró, Mossoró, 1992.

COSTA, N.D.; SOARES, J.M.; BRITO, L.T. de L.; FARIA, C.M.B. Doses de nitrogênio aplicadas via fertirrigação e densidade de plantio na cultura do melão. In: REUNIÃO BRASILEIRA DE FERTILIDADE DO SOLO E NUTRIÇÃO DE PLANTAS, 22., 1996, Manaus. Resumos... p. 196-197.

FARIA, C.M.B. de; COSTA, N.D.; PINTO, J.M.; BRITO, L.T. de L.; SOARES, J.M. Níveis de nitrogênio por fertirrigação e densidade de plan- tio na cultura do melão em um Vertissolo. Pesquisa Agropecuária Brasileira, Brasília, v.35, n.3, p.491-495, 2000.

FARIAS, J.R.B.; MATINS, S.R.; FERNANDES, H.S. Comportamento do meloeiro cultivado em estufa plástica em diferentes espaçamentos e cobertura do solo. Horticultura Brasileira, Brasília, v. 6, n.1, p.52, 1988.

GRANGEIRO,L.C.; PEDROSA, J.F.; BEZERRANETO, F; NEGREIROS, M.Z. de. Rendimento de híbridos de melão amarelo em diferentes densidades de plantio. Horticultura Brasileira, Brasília, v.17, n.2, p.200-206, 1999a.

GRANGEIRO, L.C.; PEDROSA, J.F.; BEZERRANETO, F.; NEGREIROS, M.Z. de. Qualidade de híbridos de melão amarelo em diferentes densidades de plantio. Horticultura Brasileira, Brasília, v.17, n.1, p.110-113, 1999b.

JANDEL SCIENTIFIC. User's Manual. California: Jandel Scientific, 1991. 280p.

KNAVEL, D.E. Growth, development and yield potential of short internode muskmelon. Journal of the American Society for Horticultural Science, Alexandria v.113, p.595-599, 1988.

KULTUR, F.; HARRISON, H.C.; STAUB, J.E. Spacing and genotype affect fruit sugar concentration, yield and fruit size of muskmelon. HortScience, Alexandria, v.36, n.2, p.274-278, 2001

MENDLINGER, S. Effect of increasing plant density and salinity on yield and fruit quality in muskmelon. Scientiae Horticulturae, Amsterdam, v.57, n.1, p.41-49, 1994.

MONTEIRO, A.A.; MEXIA, J.T. Influência da poda e do número de frutos por planta na qualidade dos frutos e produtividade do melão. Horticultura Brasileira, Brasília, v.6, n.1, p.9-12, 1988.

NERSON, H. Effect of population density on fruit and seed production in muskmelon. In: INTERNATIONAL SYMPOSIUM ON CUCURBITS, 1., 1997, Adana, Turkey. Leuven, Belgium: International Society for Horticultural Science, 1999.

NORUSIS, M.J. SPSS Statistics. Illinois: SPSS, 1990. 320p.

PARIS, H.S.; NERSON, H.; BRUGER, Y.; EDELSTEIN, M.; KARCHI, Z. Synchrony of yield of melons as affected by pant type and density. Journal of Horticultural Science, Ashford, v.63, n.1, p.141-147, 1988

PEDROSA, J.F.; TORRES FILHO, J.; MEDEIROS, I.B. de. Poda e densidade de plantio em melão. Horticultura Brasileira, Brasília, v.9, n.1, p.18-20, 1991 .

SCHALES, F.D.; TIMOTHY, J.N. Population density and mulch effects on muskmelon yields. HortScience, Alexandria,v. 23, n.1, p.148, 1988.

ZAHARA, M. Effects of plant density on yield and quality of Cantaloupe. California Agriculture, Oakland, v. 26, n.1, p.15, 1972. 